\title{
Salivary Gland Disorders in Children and Adolescents: A 15-year Experience
}

\author{
Donata Gellrich ${ }^{1}$ Moritz Bichler ${ }^{1} \quad$ Christoph A. Reichel ${ }^{1} \quad$ Florian Schrötzlmair $^{1}$ Pamela Zengel ${ }^{1}$
}

\author{
1 Department of Otorhinolaryngology, Head and Neck Surgery, \\ University Hospital of the Ludwig-Maximilians-University Munich, \\ Munich, Germany
}

Int Arch Otorhinolaryngol 2020;24:e31-e37.

\begin{abstract}
Address for correspondence Donata Gellrich, MD, Department of Otorhinolaryngology, Head and Neck Surgery, University Hospital of the Ludwig-Maximilians-University Munich, Marchioninistr, 15 Munich 81377, Germany (e-mail: Donata.Gellrich@med.uni-muenchen.de).
\end{abstract}

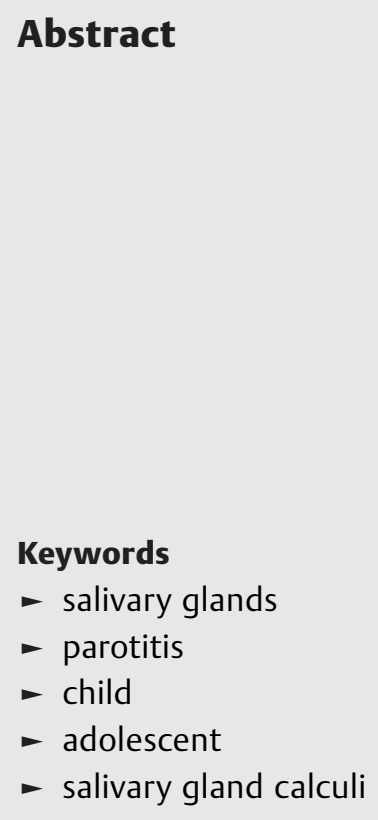

Introduction Diseases of the salivary glands are rare in children and adolescents, with the exception of viral-induced infections.

Objective To determine the clinical course of the disease, the diagnostic procedures, the treatment and the outcome of all children and adolescents affected with salivary gland diseases at our clinic over a period of 15 years.

Methods A retrospective chart review including a long-term follow-up was conducted among 146 children and adolescents treated for salivary gland disorders from 2002 to 2016. Results Diagnosing acute sialadenitis was easily managed by all doctors regardless of their specialty. The diagnosis of sialolithiasis was rapidly made only by otorhinolaryngologists, whereas diagnosing juvenile recurrent parotitis imposed difficulties to doctors of all specialties - resulting in a significant delay between the first occurrence of symptoms and the correct diagnosis. The severity-adjusted treatment yielded improvements in all cases, and a full recovery of $75 \%$ of the cases of sialolithiasis, $73 \%$ of the cases of juvenile recurrent parotitis, and $100 \%$ of the cases of acute sialadenitis.

Conclusions Due to their low prevalence and the lack of pathognomonic symptoms, salivary gland diseases in children and adolescents are often misdiagnosed, resulting in an unnecessarily long period of suffering despite a favorable outcome following the correct treatment.

\section{Introduction and Objectives}

Excluding viral-induced infections, diseases of the salivary glands are rare in children and adolescents. Corresponding to the low prevalence of salivary gland disorders in childhood, there is little evidence on this subject in the literature: most publications are limited to case reports or studies with relatively small patient numbers, and deal with single disease entities, thereby lacking any statistically significant results. A further difficulty consists in the lack of comparability of the available literature due to very heterogeneous study groups: Laskawi et al, ${ }^{1}$ for example, reported on 45 children with inflammatory salivary gland diseases, and Orvidas et $\mathrm{al}^{2}$ reported 118 children with swelling of the salivary glands. received

August 11, 2018

accepted

August 4, 2019
DOI https://doi.org/

10.1055/s-0039-1697993. ISSN 1809-9777.
The low prevalence and lack of awareness of salivary gland diseases in childhood can present management challenges regarding the diagnostic and therapeutic approaches. ${ }^{3}$ As our ear, nose and throat (ENT) department offers a weekly consultation hour for salivary gland disorders, the data involving children treated for these diseases is relatively large. Due to this patient collective, a retrospective analysis of our data seemed reasonable. The aim of the present investigation was to evaluate the quality of our management and to characterize common difficulties, to improve the care for children and adolescents suffering from salivary gland diseases.

\section{Methods}

The clinical records from 2002 to 2016 of our Department of Otorhinolaryngology were screened for pediatric salivary

Copyright $\odot 2020$ by Thieme Revinter Publicações Ltda, Rio de Janeiro, Brazil 
gland disorders. Subsequently, a retrospective chart review was performed in all 146 cases found with a maximum age of 17 years.

The following parameters were obtained from the chart review (outpatient clinic chart notes as well as hospital charts) and from questionnaires that are usually filled out by all patients with salivary gland disorders at their first consultation and later at the follow-up: age; gender; general medical history; family history; initial diagnosis and therapy preceding the consultation at our department; time delay and number of doctor consultations until the correct diagnosis was made; cardinal symptoms; number and duration of disease episodes prior to the actual therapy; pain prior to therapy; and outpatient treatment or hospitalization. Furthermore, the data from the local clinical examination and every diagnostic procedure performed, as well as the type of therapy, were retrieved from the medical records.

For the assessment of the outcome, the data from the follow-up examinations were analyzed focusing on the following parameters: number of acute disease episodes since therapy, and pain, if so, after therapy (Likert-type scale ranging from 0 [no pain] to 6 [the worst degree of pain]).

The data were summarized into four subgroups according to the underlying diagnosis: sialolithiasis (group 1); juvenile recurrent parotitis (JRP, group 2); acute sialadenitis of unknown origin (group 3); and other salivary gland disorders (group 4). The data analysis was performed for each of the four groups separately.

The retrospective study described was performed in accordance with the Declaration of Helsinki, and it was approved by the local ethics committee (project number 18-231) and the data protection commissioner. After the collection, all data were anonymized prior to analysis.

The statistical analysis was performed using the SigmaStat (Jandel Corp., San Rafael, CA, US) software. All of the data failed the normality test. For the descriptive statistics of the four subgroups, we used median values. In order to compare the intensity of the pain before and after therapy, the Wilcoxon signed-rank test was used. Further, the KruskalWallis test and the Dunn method as a post-hoc test were used to compare the age distribution among the different groups. Values of $p<0.05$ were considered statistically significant.

\section{Results}

A total of 146 patients with salivary gland disorders were enrolled and had their charts reviewed. The most frequent diagnosis among our sample was JRP $(n=44)$, followed by sialolithiasis $(n=36)$, acute unilateral sialadenitis of unknown origin $(n=32)$, and other salivary gland disorders $(n=34)$. The demographic data and clinical characteristics of all patients are presented in -Table $\mathbf{1}$.

The age ranged from 6 months to 17 years. Patients affected by JRP were significantly younger, with a median age of 4 years, compared with all other analyzed disease entities (KruskalWallis test: $p<0.001$; post-hoc test: $p<0.05$ ).

A predominance of male patients was observed in both groups of inflammatory diseases, as well as among the patients with sialolithiasis (JRP: $59 \%$ of male patients; $95 \%$ confidence interval: $44.4-72.3 \%$; acute sialadenitis: $62 \%$ of male patients; $95 \%$ confidence interval: 45.2-77.1\%; sialolithiasis: $69 \%$ of male patients; $95 \%$ confidence interval: $53.0-$ $82.1 \%)$. Apart from a generally higher incidence of inflammatory salivary gland disorders among males, boys needed to be hospitalized about twice as often as girls.

Family history was only positive in 5 (14\%) cases of sialolithiasis and in 3 (7\%) cases of JRP.

As shown in - Table 1, the clinical picture of all patients was dominated by swelling, often accompanied by pain, and, less frequently, by redness. A single distinctive clinical feature could be found in patients with sialolithiasis: 29 (91\%) of the 32 patients who reported pain due to sialolithiasis described a pain clearly linked to meals.

Concerning the diagnostic tools, every patient underwent the clinical examination. In patients with acute sialadenitis of unknown origin, diagnostic tools beyond the clinical examination were frequently resigned. However, in 17 (53\%) of the 32 cases, further diagnostic tools (ultrasonography, laboratory measurements) were performed. In patients with sialolithiasis, the clinical examination also turned out to be helpful: $78 \%$ of the calculi located in the submandibular duct could be palpated bimanually. The ultrasound identified $70 \%$ of the salivary stones. The combination of palpation and ultrasound yielded a detection rate of $89 \%$ (32 out of 36 stones identified). A total of four calculi (11\%) were only confirmed by sialendoscopy.

In the JRP group, all patients underwent ultrasound, at least unilaterally, at the swollen parotid gland, showing multiple hypoechoic areas in the glandular parenchyma and, during acute disease episodes, a hypervascularization in the Doppler ultrasound.

In most cases of other salivary gland disorders, further diagnostic tools (such as magnetic resonance imaging [MRI], computed tomography [CT] or fine needle aspiration) were used due to the variety of revealed diagnoses.

The therapeutic management of our patients varied greatly depending on the diagnosis: for sialolithiasis and JRP, the therapy prescribed to our patients was conducted gradually from conservative solutions to more invasive procedures. In cases of acute sialadenitis of unknown origin, all patients were treated conservatively. - Table 2 summarizes the different treatment options chosen together with their indication and the yielded relief of symptoms following therapy. In the group of other salivary gland disorders, the treatment regimen was as individual as the disease entity, and these data are presented in - Table 3 .

Follow-up was achieved in 28 (78\%) out of 36 patients in group 1 (sialolithiasis), in 37 (84\%) out of 44 patients in group 2 (JRP), in 19 (60\%) out of 32 patients in group 3 (acute sialadenitis of unknown origin), and in 30 (88\%) out of 34 patients in group 4 (salivary gland diseases other than the ones classified in groups 1 to 3 ). Some follow-ups were not possible, as 32 patients could not be contacted due to unlisted changes in postal addresses and telephone numbers. The mean follow-up of the sample was 3.4 years, with a minimum of 9 months and a maximum of 12.3 years. 
Table 1 Demographic and clinical characteristics of the patients divided by underlying disease entity

\begin{tabular}{|l|l|l|l|l|}
\hline $\begin{array}{l}\text { Demographic and clinical } \\
\text { characteristics }\end{array}$ & $\begin{array}{l}\text { Sialolithiasis } \\
(\boldsymbol{n}=36)\end{array}$ & $\begin{array}{l}\text { Juvenile recurrent } \\
\text { parotitis } \\
(\boldsymbol{n}=44)\end{array}$ & $\begin{array}{l}\text { Acute sialadenitis of } \\
\text { unknown origin } \\
(\boldsymbol{n}=32)\end{array}$ & $\begin{array}{l}\text { Other salivary } \\
\text { gland disorders } \\
(\boldsymbol{n}=34)\end{array}$ \\
\hline Gender & & & & \\
\hline Male & $25(69 \%)$ & $26(59 \%)$ & $20(62 \%)$ & $14(41 \%)$ \\
\hline Female & $11(31 \%)$ & $18(41 \%)$ & $12(38 \%)$ & $20(59 \%)$ \\
\hline Median age (years) & 12 & 4 & 12 & 9 \\
\hline Minimum age (years) & 6 & 2 & 1 & 0.5 \\
\hline Maximum age (years) & 17 & 17 & 18 & 17 \\
\hline Positive family history & $5(14 \%)$ & $3(7 \%)$ & 0 & 0 \\
\hline Affected Gland & & & & \\
\hline Submandibular & $36(100 \%)$ & 0 & $8(25 \%)$ & $10(29 \%)$ \\
\hline Parotid & 0 & $44(100 \%)$ & $24(75 \%)$ & $17(50 \%)$ \\
\hline Sublingual & 0 & 0 & 0 & $7(21 \%)$ \\
\hline Leading symptom(s) & & & $32(100 \%)$ & \\
\hline Swelling & $34(94 \%)$ & $40(91 \%)$ & $31(97 \%)$ & $35(97 \%)$ \\
\hline Pain & $32(89 \%)$ & $32(73 \%)$ & $17(53 \%)$ & $7(39 \%)$ \\
\hline Redness & 0 & $8(18 \%)$ & $13(30 \%)$ & $30(88 \%)$ \\
\hline Rate of hospitalization & $22(61 \%)$ & $13(30 \%)$ & $10(50 \%)$ & $14(100 \%)$ \\
\hline Males & $15(60 \%)$ & $10(38 \%)$ & $3(25 \%)$ & $16(80 \%)$ \\
\hline Females & $7(63 \%)$ & $3(17 \%)$ & & \\
\hline
\end{tabular}

Note: Except for the age, the values represent the total number of patients and the percentage of each evaluated subgroup.

During the follow-up, many patients stated that they were symptom-free directly after the treatment. In all of the remaining cases, a significant improvement was observed in terms of a reduction in the intensity of the pain after therapy. The intensity of the pain was significantly reduced in all groups after the therapy (see - Fig. 1: on a visual analogue scale from 0 [prior to therapy] to 6 [after therapy]: in the sialolithiasis group, the reduction was from 3.9 to 0.5 ; in the JRP group, from 3.8 to 0.6 ; and in the acute sialadenitis group, from 4.4 to 0.0 ). In the group with JRP, a chronic disease, a reduction in the average number of episodes from 12.0 (before therapy) to 0.6 (after therapy) was recorded. Further, the ultrasound yielded a sonographic improvement.

-Fig. 2 demonstrates how many days the patients in each group had to wait and how many doctors they had to see to receive the correct diagnosis. The medical diagnosis of acute sialadenitis is routine and effective, with an average of 1.1 consultations. In cases of sialolithiasis, however, 2.16 consultations were necessary until the correct diagnosis was made, at which time the symptoms had lasted for an average of nearly five months. In 16 (44\%) out of 36 patients, the correct diagnosis of sialolithiasis had already been made before the admission to our department, all by ENT doctors, except for 1 (3\%) case, which had been correctly diagnosed by a pediatrician. In the remaining 20 (56\%) cases, the preceding doctors (including ENT doctors, pediatricians, dentists and general practitioners) had failed to correctly diagnose sialolithiasis.
On average, the JRP patients in our study group had to wait 684 days, and had to see a doctor 4 times to receive the correct diagnosis. In 8 (18.2\%) cases, JRP had been correctly diagnosed before the admission to our department, 4 times by ENT doctors, 3 times by pediatricians, and once by a general practitioner. In the remaining 36 (81.8\%) cases, JRP was misdiagnosed, most frequently as an acute parotitis (in 18 patients, $41 \%$ ) or mumps (in 8 patients, $18 \%$ ), leading to the administration of at least one antibiotic and, more commonly, of several antibiotics.

\section{Discussion}

Considering the long observation time of 15 years and the fact that our hospital is a large medical center with a special team well-versed in salivary gland disorders, the small number of 146 cases is a reflection of the rareness of pediatric salivary gland diseases reported in other studies. ${ }^{2,4}$

Acute and chronic inflammations of the salivary glands were the most frequently diagnosed diseases, as described in the literature. ${ }^{2}$ However, the diagnosis of acute sialadenitis, found in less than $1 / 4$ of our study population, is clearly underrepresented, possibly due to the fact that most children with uncomplicated viral sialadenitis are sufficiently treated by pediatricians and, therefore, do not frequently seek experts at the university ENT Department.

For all three of the most frequent diseases (sialolithiasis, JRP, acute sialadenitis), we found a predominance of male 
Table 2 Different treatment options combined with the indication and the rate of cases that became symptom-free

\begin{tabular}{|c|c|c|}
\hline $\begin{array}{l}\text { Therapy for sialolithiasis } \\
\text { (number of treated patients) }\end{array}$ & Indication & $\begin{array}{l}\text { Rate of symptom-free } \\
\text { cases }\end{array}$ \\
\hline $\begin{array}{l}\text { Sialogogue and salivary gland massage } \\
(n=5)\end{array}$ & $\begin{array}{l}\text { Conservative treatment regimen as the first step } \\
\text { in a graded therapy }\end{array}$ & $80 \%$ \\
\hline $\begin{array}{l}\text { Removal by endoscopy }+I \text { - papillotomy } \\
(n=7)\end{array}$ & $\begin{array}{l}\text { Failed conservative treatment; intraductal } \\
\text { location of the stone (stone }<5 \mathrm{~mm} \text { ) }\end{array}$ & $71 \%$ \\
\hline $\begin{array}{l}\text { Transoral surgical removal } \\
(n=18)\end{array}$ & Intraductal location of the stone (stone $>5 \mathrm{~mm}$ ) & $67 \%$ \\
\hline $\begin{array}{l}\text { Extracorporeal shock wave lithotripsy (ESWL) } \\
(n=2)\end{array}$ & Intraparenchymal location of the stone & $100 \%$ \\
\hline $\begin{array}{l}\text { ESWL prior to transoral surgical removal } \\
(n=2)\end{array}$ & $\begin{array}{l}\text { Intraparenchymal location of the stone, intra- } \\
\text { ductal location of the stone after ESWL }\end{array}$ & $100 \%$ \\
\hline $\begin{array}{l}\text { ESWL prior to endoscopy and papillotomy } \\
(n=1)\end{array}$ & $\begin{array}{l}\text { Intraparenchymal location of the stone, intra- } \\
\text { papillary location of the stone after ESWL }\end{array}$ & $100 \%$ \\
\hline $\begin{array}{l}\text { Submandibulectomy } \\
(n=1)\end{array}$ & Two failed attempts at transoral surgical removal & $100 \%$ \\
\hline $\begin{array}{l}\text { Therapy for juvenile recurrent parotitis } \\
\text { (number of treated patients) }\end{array}$ & Indication & $\begin{array}{l}\text { Rate of symptom-free } \\
\text { cases }\end{array}$ \\
\hline $\begin{array}{l}\text { Sialogogue, salivary gland massage, ibuprofen } \\
(n=23)\end{array}$ & $\begin{array}{l}\text { Conservative treatment regimen as the first step } \\
\text { in a graded therapy }\end{array}$ & $83 \%$ \\
\hline Antibiotics $(n=6)$ & Clinical signs of bacterial superinfection & $83 \%$ \\
\hline $\begin{array}{l}\text { Sialendoscopy with lavage and predinosolone } \\
(n=15)\end{array}$ & $>5$ episodes per year & $53 \%$ \\
\hline $\begin{array}{l}\text { Therapy for acute sialadenitis (number of } \\
\text { treated patients) }\end{array}$ & Indication & $\begin{array}{l}\text { Rate of symptom-free } \\
\text { cases }\end{array}$ \\
\hline $\begin{array}{l}\text { Sialogogue, salivary gland massage, ibuprofen } \\
(n=5)\end{array}$ & $\begin{array}{l}\text { Mild symptoms without clinical signs of bacterial } \\
\text { infection }\end{array}$ & $100 \%$ \\
\hline Per os antibiotics $(n=14)$ & Clinical signs of bacterial infection & $100 \%$ \\
\hline Intravenous antibiotics $(n=10)$ & No improvement following oral antibiotics & $100 \%$ \\
\hline $\begin{array}{l}\text { Intravenous antibiotics }+ \text { intravenous } \\
\text { prednisolone } \\
(n=3)\end{array}$ & $\begin{array}{l}\text { No improvement following oral antibiotics and } \\
\text { more severe clinical picture }\end{array}$ & $100 \%$ \\
\hline
\end{tabular}

Note: Concerning the rate of symptom-free cases, the values represent the percentage of each evaluated subgroup.

patients. Concerning the gender ratio for sialolithiasis and acute sialadenitis, contradictory results are found in the literature, whereas a clear predominance is reported for JRP patients. ${ }^{5-7}$ Further, our data clearly demonstrate that JRP and acute sialadenitis do not only affect boys more frequently than girls, but that boys are also more severely affected by the disease, as they needed to be hospitalized twice as often as girls. However, we found no comparative data in the literature.

Among patients with sialolithiasis and JRP, there was a positive family medical history. To our knowledge, there is only one paper discussing the heredity of salivary stones, ${ }^{8}$ whereas there is clear evidence for an autosomal dominant inheritance in JRP patients. ${ }^{9}$

Concerning the diagnostic tools, the clinical examination and ultrasonography are sufficient in most cases. In cases of sialolithiasis, bimanual palpation appears to be very helpful, given the fact that most salivary stones in children are located distally in the duct. ${ }^{10}$ Although the ultrasound of the salivary glands is usually considered the imaging method with the highest sensitivity, ${ }^{11}$ this technique identified only $25(69 \%)$ of all 36 salivary stones in our study group. This rather substandard result might be explained by the large number of non-standardized examiners. As stated in the literature, ${ }^{12}$ the sonographic detection rate of salivary stones depends to a high degree on the personal skills of the examiner. The rate of undetected stones could possibly be reduced by CT scans or digital volume tomography, which we, however, refrained from due to the high radiation exposure.

In cases of JRP, the ultrasound turned out to be very helpful in the diagnosis, as it was in all cases positive for typical sonographic signs of JRP in our sample. In other studies, the ultrasound successfully confirmed the affection of the parotid gland by JRP to be bilateral despite isolated unilateral swelling. ${ }^{6,13}$ Therefore, both parotid glands should be examined by ultrasound even if swelling is clearly limited only to one side, particularly since a bilateral sonographic 
Table 3 Other salivary gland disorders $(n=34)$, their treatment and the rate of symptom-free cases

\begin{tabular}{|l|l|l|}
\hline $\begin{array}{l}\text { Salivary gland disorder } \\
\text { (number of treated patients) }\end{array}$ & Therapy & $\begin{array}{l}\text { Rate of symptom-free } \\
\text { cases }(\%)\end{array}$ \\
\hline Hemangioma $(\boldsymbol{n}=\mathbf{3})$ & $\begin{array}{l}\text { Wait and scan }(n=2) ; \\
\text { resection by lateral parotidectomy }(n=1)\end{array}$ & $100 \%$ \\
\hline Ranula $(\boldsymbol{n}=\mathbf{7})$ & $\begin{array}{l}\text { Surgical removal with extirpation of the sublin- } \\
\text { gual salivary gland }\end{array}$ & $100 \%$ \\
\hline Parotid cysts $(\boldsymbol{n}=\mathbf{4})$ & $\begin{array}{l}\text { Wait and scan }(n=3) ; \\
\text { injection of picibanil }(n=1)\end{array}$ & $100 \%$ \\
\hline Abscess formation $(\boldsymbol{n}=\mathbf{4})$ & Incision & $100 \%$ \\
\hline $\begin{array}{l}\text { Odontogenic sialadenitis of the submandibular } \\
\text { gland }(\boldsymbol{n}=\mathbf{2})\end{array}$ & Tooth extraction and antibiotics & $100 \%$ \\
\hline Stricture of the excretory duct $(\boldsymbol{n}=\mathbf{4})$ & Surgical removal & $100 \%$ \\
\hline Lymphangioma $(\boldsymbol{n}=\mathbf{6})$ & Injection of picibanil & $100 \%$ \\
\hline $\begin{array}{l}\text { Multiple ectasia of the excretory duct of one } \\
\text { parotid gland }(\boldsymbol{n}=\mathbf{1})\end{array}$ & Antibiotics & $100 \%$ \\
\hline Pleomorphic adenoma $(\boldsymbol{n}=\mathbf{1})$ & Surgical removal by lateral parotidectomy & $100 \%$ \\
\hline $\begin{array}{l}\text { Hyperplastic intraparotid lymph node } \\
(\boldsymbol{n}=\mathbf{1})\end{array}$ & Surgical removal by extracapsular dissection & $100 \%$ \\
\hline Acinic cell carcinoma $(\boldsymbol{n}=\mathbf{1})$ & Surgical removal by total parotidectomy & $100 \%$ \\
\hline
\end{tabular}

Note: Concerning the rate of symptom-free cases, the values represent the percentage of each evaluated subgroup.

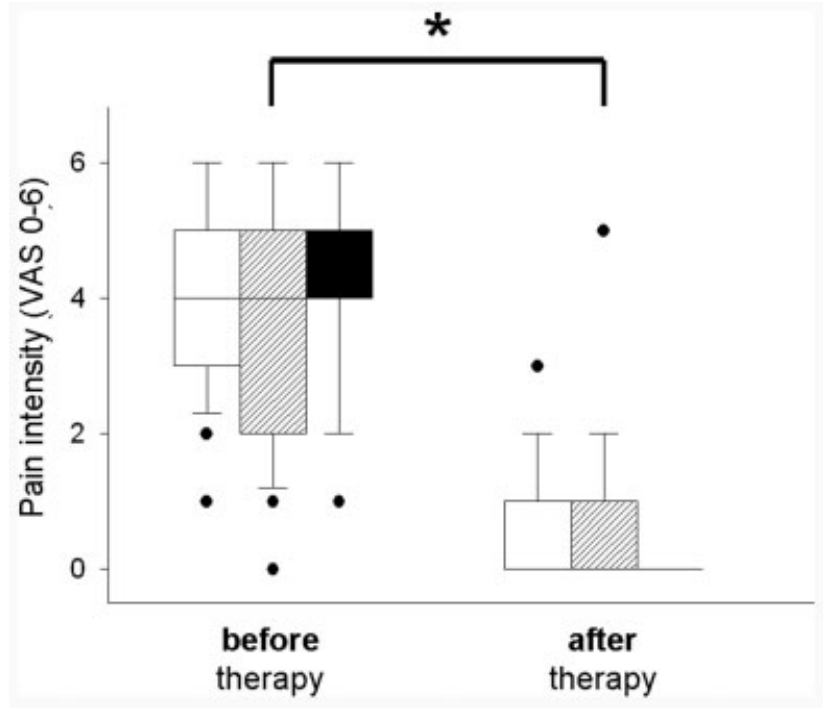

Fig. 1 Pain intensity before and after therapy in cases of sialolithiasis (white box), JRP (gray box) and acute sialadenitis of unknown origin (black box). In these three groups, the pain was significantly reduced after the therapy. Abbreviation: VAS, visual analogue scale. Note: ${ }^{*} p<0.05$. affection facilitates the diagnostic demarcation between an acute exacerbation of JRP and an acute sialadenitis. Furthermore, the ultrasound can help exclude other diagnoses like neoplasms, which is why it is recommended as a valuable tool for the initial diagnosis as well as for follow-up examinations. $^{14}$

In most cases of other salivary gland disorders, further diagnostic tools (such as MRI, CT or fine needle aspiration) were performed in addition to the compulsory ultrasound.

The therapeutic management depends on the diagnosis: for sialolithiasis, the treatment should be conducted gradually from conservative solutions to more invasive procedures, depending on the size, location and mobility of the stone. In our study group, 4 (11\%) of the 36 patients became symptom-free under strict conservative management. Following the conservative treatment, an endoscopic procedure can be performed as a more invasive, but gland-preserving approach for small ( $<5 \mathrm{~mm}$ ) and mobile stones. ${ }^{15}$ Transoral surgical removal is an appropriate technique to treat sialoliths persisting in the duct. Extracorporeal shockwave lithotripsy (ESWL), which was performed in five cases (14\%) out of
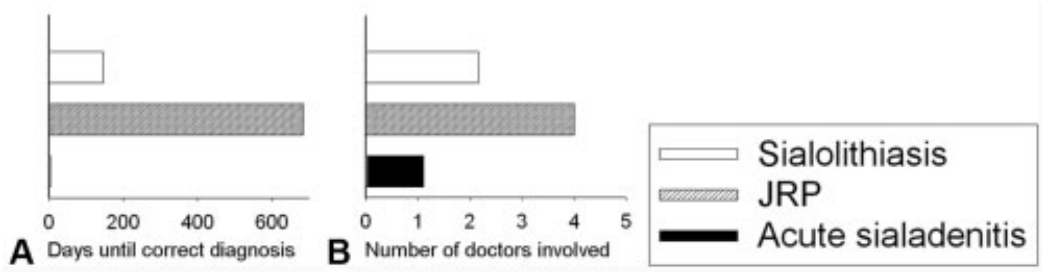

Fig. 2 Time delay (A) and number of doctors involved (B) until the correct diagnosis was made. (A) Sialolithiasis was correctly diagnosed after an average of 144 days (white column), and JRP, after an average of 684 days (gray column), whereas acute sialadenitis was recognized after an average of 3 days (black column); (B) on average, only 1.1 doctors were involved until the correct diagnosis of acute sialadenitis was made (black column), whereas 2.16 doctors had to be seen for the right diagnosis of sialolithiasis (white column), and 4.0 for JRP (gray column). 
36 cases in our study group, is indicated if the calculus cannot be visualized endoscopically due to its intraparenchymal location or its impaction on the wall of the efferent duct. ${ }^{16}$ Submandibulectomy, which was only necessary in one case (3\%) out of 36 cases in our study group, should remain the ultima ratio. The follow-up results of full recovery in 27 (75\%) of the 36 cases and symptom improvement in all 36 (100\%) cases confirms the recent recommendations for a graded therapy in cases of pediatric sialolithiasis. ${ }^{17}$

The therapeutic management of JRP in our hospital was individual, primarily depending of the frequency of acute episodes. The threshold of five episodes per year for indication for sialendoscopy was chosen according to the recommendation by Canzi et $\mathrm{al}^{7}$ in 2013. Following the sialendocopy including lavage, $8(53 \%)$ out of 15 patients were completely free of symptoms. In the remaining 7 (47\%) cases in which the disease was not completely resolved by endoscopic lavage, a significant reduction in future disease episodes was observed. Other authors confirm a high success rate of $\sim 90 \%$ after a single intervention. ${ }^{13,18}$ Critical readers may argue that up to $92 \%$ of the JRP patients will be free of symptoms within 5 years without undergoing any treatment. ${ }^{19}$ However, a recent study comparing the efficacy of sialendoscopic lavage with antibiotic therapy confirmed that a faster regression of the symptoms can be achieved by means of the lavage. ${ }^{20}$ Roby et $\mathrm{al}^{21}$ stated that even ductal corticosteroid infusion alone has similar results as sialendoscopy with corticosteroid lavage. Repeated antibiotic treatment, though, bears the risk of antimicrobial resistance development as well as of gastrointestinal disorders. Despite the fact that antibiotics are efficient in the treatment of acute JRP episodes and may be administered as a first-line therapy, at least in acute episodes, ${ }^{20}$ we tried to avoid antibiotics, as bacterial infections are not very likely to be the only pathogenesis of JRP. ${ }^{22,23}$ Therefore, the administration of antibiotics is not a causal therapy, and should be limited to cases of acute bacterial superinfection. In acute disease episodes with no signs of bacterial superinfection, the first-line treatment should be analgesics, sialogogues and sufficient hydration only. The healing rate of $73 \%$ ( 32 out of 44 patients) and an improvement in symptoms in $100 \%$ ( 44 out of 44 patients) confirm the efficacy of our treatment management and suggest a clear advantage of treating the JRP compared with waiting for the natural self-resolution of the disease by puberty. As the peak age of onset in our study group was at 4 years of age, the $100 \%$ response to therapy within 12 months cannot be explained by the occurrence of puberty.

The medical diagnosis of acute sialadenitis is efficient in the daily routine. However, the need for antibiotics in 27 patients (84\%) out of 32 cases has to be questioned. Highly increased levels of inflammation related to hematological parameters that are typical signs of bacterial infections were only found in 7 (50\%) out of 14 cases (data not shown). Subsequently, we must hypothesize that some viral-induced infections were unnecessarily treated with antibiotics. A higher degree of diagnostic safety might be provided by antigen or antibody testing for the most common viruses possibly inducing sialadenitis, as suggested by Davidkin et al. ${ }^{24}$ However, the high cost of this test does not enable its routine implementation. It is our expert opinion that the consequent consideration of all present clinical findings is a more feasible test for the need for antibiotics: fever, purulent secretion and reduced general condition.

With regard to other salivary gland disorders, all patients were free of symptoms at the follow-up, proving that the treatment of rare salivary gland disorders in children can be unproblematic provided that the correct diagnosis is made. The typical finding that half of all salivary gland tumors are malignant in children was confirmed in our study group. ${ }^{4}$

A comparison of the symptoms reveals that no clinical sign is pathognomonic for one single diagnosis. This difficulty combined with the rareness of salivary gland disorders among children might be the main reason for the frequent delay and the large number of doctors involved until a correct diagnosis is made, which is shown in - Fig. 2. Acute sialadenitis was rapidly diagnosed by doctors of all specialties. Diagnosing JRP, however, imposed difficulties to all doctors regardless of their specialty. Only regarding sialolithiasis, a difference between various specialties was observed: pediatric doctors, dentists and general practitioners failed to diagnose the sialolithiasis properly, whereas most ENT doctors rapidly recognized it. This is certainly due to the fact that the symptoms of sialolithiasis are well-known regarding adult ENT patients, for whom the prevalence is much higher.

\section{Conclusion}

Pediatric salivary gland diseases are rare, except for viralinduced diseases. Merely considering the symptoms does not provide sufficient information to make the correct diagnosis. However, in most cases, a combination of medical history, including cardinal symptoms, clinical status and examination by ultrasound proved to be sufficient to indicate the appropriate therapeutic approach. Although these diagnostic tools are available in most ENT and pediatric practices, our data show a huge delay between the first occurrence of symptoms and the adequate treatment, especially in patients with sialolithiasis and JRP, which results in an unnecessarily long period of suffering for the young patients. However, in most patients, good healing rates can be achieved provided that the adequate therapy is performed, ideally adjusted to the severity of the symptoms. To spare children unnecessary pain and suffering in the future, the main challenge is to improve the awareness of pediatric salivary diseases, especially JRP, among ENT and pediatricians.

\section{Conflicts of Interest}

The authors have none to declare.

\section{References}

1 Laskawi R, Schaffranietz F, Arglebe C, Ellies M. Inflammatory diseases of the salivary glands in infants and adolescents. Int $\mathrm{J}$ Pediatr Otorhinolaryngol 2006;70(01):129-136

2 Orvidas LJ, Kasperbauer JL, Lewis JE, Olsen KD, Lesnick TG. Pediatric parotid masses. Arch Otolaryngol Head Neck Surg 2000;126(02):177-184 
3 Jablenska L, Trinidade A, Meranagri V, Kothari P. Salivary gland pathology in the paediatric population: implications for management and presentation of a rare case. J Laryngol Otol 2014;128(01):104-106

4 Ellies M, Laskawi R. Diseases of the salivary glands in infants and adolescents. Head Face Med 2010;6:1

5 Leerdam CM, Martin HC, Isaacs D. Recurrent parotitis of childhood. J Paediatr Child Health 2005;41(12):631-634

6 Zenk J, Koch M, Klintworth N, Iro H. [Chronic recurrent parotitis]. HNO 2010;58(03):237-243

7 Canzi P, Occhini A, Pagella F, Marchal F, Benazzo M. Sialendoscopy in juvenile recurrent parotitis: a review of the literature. Acta Otorhinolaryngol Ital 2013;33(06):367-373

8 Bullock KN. Parotid and submandibular duct calculi in three successive generations of one family. Postgrad Med J 1982;58 (675):35-36

9 Wiedemann HR. Salivary gland disorders and heredity. Am J Med Genet 1997;68(02):222-224

10 Chung MK, Jeong HS, Ko MH, et al. Pediatric sialolithiasis: what is different from adult sialolithiasis? Int J Pediatr Otorhinolaryngol 2007;71(05):787-791

11 Welkoborsky HJ. [Current aspects in ultrasonography of the salivary glands]. HNO 2011;59(02):155-165

12 Katz P, Hartl DM, Guerre A. Clinical ultrasound of the salivary glands. Otolaryngol Clin North Am 2009;42(06):973-1000

13 Nahlieli O, Shacham R, Shlesinger M, Eliav E. Juvenile recurrent parotitis: a new method of diagnosis and treatment. Pediatrics 2004; 114(01):9-12

14 Capaccio P, Sigismund PE, Luca N, Marchisio P, Pignataro L. Modern management of juvenile recurrent parotitis. J Laryngol Otol 2012;126(12):1254-1260
15 Maresh A, Kutler DI, Kacker A. Sialoendoscopy in the diagnosis and management of obstructive sialadenitis. Laryngoscope 2011; 121(03):495-500

16 Iro $\mathrm{H}$, Zenk J, Koch M. [Modern concepts for the diagnosis and therapy of sialolithiasis]. HNO 2010;58(03):211-217

17 Al-Nawas B, Beutner D, Geisthoff U, et al. [The new S2K AWMF guideline for the treatment of obstructive sialadenitis in commented short form].Laryngorhinootologie 2014;93:87-94

18 Shacham R, Droma EB, London D, Bar T, Nahlieli O. Longterm experience with endoscopic diagnosis and treatment of juvenile recurrent parotitis. JOral Maxillofac Surg 2009;67(01): 162-167

19 Geterud A, Lindvall AM, Nylén O. Follow-up study of recurrent parotitis in children. Ann Otol Rhinol Laryngol 1988;97(4 Pt 1):341-346

20 Schneider H, Koch M, Künzel J, et al. Juvenile recurrent parotitis: a retrospective comparison of sialendoscopy versus conservative therapy. Laryngoscope 2014;124(02):451-455

21 Roby BB, Mattingly J, Jensen EL, Gao D, Chan KH. Treatment of juvenile recurrent parotitis of childhood: an analysis of effectiveness. JAMA Otolaryngol Head Neck Surg 2015;141(02):126-129

22 Iro H, Zenk J. [Salivary gland diseases in childhood]. Laryngorhinootologie 2014;93(Suppl 1):S103-S125

23 Ericson S, Sjöbäck I. Salivary factors in children with recurrent parotitis. Part 2: Protein, albumin, amylase, IgA, lactoferrin lysozyme and kallikrein concentrations. Swed Dent J 1996;20(05): 199-207

24 Davidkin I, Jokinen S, Paananen A, Leinikki P, Peltola H. Etiology of mumps-like illnesses in children and adolescents vaccinated for measles, mumps, and rubella. JInfect Dis 2005;191(05): 719-723 